\title{
Hypoglycemia Communication in Primary Care
}

J Gen Intern Med 36(8):2473

DOI: $10.1007 / \mathrm{s} 11606-021-06907-1$

(C) Society of General Internal Medicine 2021

$\mathrm{T}_{\mathrm{w}}$ o the Editors:

We read with great interest the review article by Dr Pilla et al., "Hypoglycemia Communication in Primary Care Visits for Patients with Diabetes" published recently in the Journal of General Internal Medicine. ${ }^{1}$ In this qualitative study, the authors analyzed 83 audio-recorded primary care visits from one urban health practice in the USA to determine the frequency and content of hypoglycemia communication in primary care visits. The authors concluded that in this high hypoglycemia risk population, communication about interval hypoglycemia and counselling for hypoglycemia prevention occurred in a minority of visits.

The authors presented excellent insight into general practice counselling related to hypoglycemia, and we do not have any criticism of the study. As the article might also serve as a useful outline for similar future studies, we would like to offer two more hypoglycemia-related topics which might be added into a prospective investigation.

The presence of nocturnal hypoglycemia should also be monitored during these physician visits. A study with blinded continuous glucose monitor in type 2 diabetes individuals revealed a substantial number of hypoglycemia episodes that occurred at night and were unnoticed. ${ }^{2}$ These events were found in patients treated with insulin and those treated with oral antidiabetics. Another study focused on non-severe nocturnal hypoglycemic events found their negative effect on subjects in the areas of diabetes self-management, sleep quality, and subject function. ${ }^{3}$ Main symptoms which point at nocturnal hypoglycemia are vivid dreams, nightmares, morning headache, poor-quality sleep, restless behaviour during sleep, chronic fatigue, lethargy, depression, disturbed or damp bedclothes, night sweats, and nocturnal convulsions. ${ }^{4}$

Older people with T2DM differ from younger people with respect to other aspects of hypoglycemia. Hypoglycemia in older patients often presents with some neurological symptoms (such as lightheadedness and unsteadiness, incoordination and ataxia, slurring of speech, and visual disturbances) and is either not identified as hypoglycemia or is misdiagnosed as other medical disorders. Cerebrovascular disease is often suggested to be the cause as the symptoms resemble those of a transient ischemic attack. ${ }^{5}$

With great respect, we suggest considering these comments if the study continuation is planned.

\author{
Jan Brož, $M D^{1}$ \\ Klára Brožová, $M D^{2}$ \\ ${ }^{1}$ Department of Internal Medicine University Hospital \\ Motol, Second Faculty of Medicine, Charles \\ University, \\ Prague, Czech Republic \\ ${ }^{2}$ Department of Pediatric Neurology, Thomayer \\ University Hospital, \\ Prague, Czech Republic
}

Corresponding Author: Jan Brož, MD; Department of Internal Medicine University Hospital Motol, Second Faculty of Medicine, Charles University, Prague, Czech Republic (e-mail: zorb@seznam.cz).

Funding This work was supported by $M H C Z$ - DRO (Thomayer University Hospital - TH, 00064190).

\section{Declarations:}

Conflict of Interest: The authors declare that they do not have a conflict of interest.

\section{REFERENCES}

1. Pilla SJ, Park J, Schwartz JL, et al. Hypoglycemia Communication in Primary Care Visits for Patients with Diabetes. J Gen Intern Med. 2021. https://doi.org/10.1007/s11606-020-06385-x.

2. Weber KK, Lohmann T, Busch K, Donati-Hirsch I, Riel R. High frequency of unrecognized hypoglycaemias in patients with Type 2 diabetes is discovered by continuous glucose monitoring. Exp Clin Endocrinol Diabetes. 2007;115(8):491-4.

3. Brod M, Christensen T, Bushnell DM. Impact of nocturnal hypoglycemic events on diabetes management, sleep quality, and next-day function: results from a four-country survey. J Med Econ. 2012;15(1):77-86.

4. Allen KV, Frier BM. Nocturnal hypoglycemia: clinical manifestations and therapeutic strategies toward prevention. Endocr Pract. 2003;9(6):530-43.

5. Jaap AJ, Jones GC, McCrimmon RJ, Deary IJ, Frier BM. Perceived symptoms of hypoglycaemia in elderly type 2 diabetic patients treated with insulin. Diabet Med. 1998;15(5):398-401.

Publisher's Note: Springer Nature remains neutral with regard to jurisdictional claims in published maps and institutional affiliations. 